Сравнение эффективности

субакромиального введения обогащенной тромбоцитами плазмы и гиалуроновой кислоты при хронической боли в области плеча, вызванной поражением сухожилий мышц вращающей манжеты плеча, по данным 6-месячного открытого клинического исследования

\author{
В.А. Нестеренко*, А.Е. Каратеев, М.А. Макаров, Е.И. Бялик, С.А. Макаров, А.М. Лила
}

\begin{abstract}
ФГБНУ «Научноисследовательский институт ревматологии им. В.А. Насоновой» 115522, Российская Федерация, Москва, Каширское шоссе, д. $34 \mathrm{a}$
\end{abstract}

V.A. Nasonova Research Institute of Rheumatology, Moscow, Russia. 34A Kashirskoe highway. Moscow, 115522

\section{Контакты:}

B.А. Нестеренко swimguy91@mail.ru

\section{Contacts:}

Vadim Nesterenko swimguy91@ mail.ru

Поступила 07.09.20
Локальные инъекции обогащенной тромбоцитами плазмы и гиалуроновой кислоты рассматриваются как эффективный метод лечения хронической боли в области плеча, связанной с поражением сухожилий мышц вращающей манжеты плеча.

Цель исследования - сравнить эффективность и безопасность локальной терапии обогащенной тромбоцитами плазмой и гиалуроновой кислотой у пациентов с хронической болью в области плеча, вызванной поражением сухожилий мышц вращающей манжеты плеча.

Материал и методы. В исследование были включены 100 пациентов (54\% женщин и 46\% мужчин, средний возраст $51,5 \pm 15,1$ года) с хронической болью в области плеча (сохраняющейся на протяжении $\geqslant 3$ мес.), связанной с повреждением и тендинитом надостной, подостной, подлопаточной или малой круглой мышц, подтвержденными данными магнитно-резонансной томографии или ультразвукового исследования. Пациенты были рандомизированы в две группы по 50 человек, в которых было проведено лечение обогащенной тромбоцитами плазмой (три инъекции с интервалом 7 дней) или ГлК (две инъекции с интервалом 7 дней). Инъекции выполнялись под контролем УЗИ в субакромиальную сумку. Результаты исследования оценивались по динамике интенсивности боли (по визуальной аналоговой шкале, 100 мм) и функциональных нарушений (индексы ASES и CSS) через 1, 3 и 6 мес.

Результаты. На фоне использования обогащенной тромбоцитами плазмы и гиалуроновой кислоты отмечалось существенное улучшение состояния пациентов, при этом оба препарата показали примерно одинаковую эффективность. Выраженность боли по визуальной аналоговой шкале через 6 месяцев снизилась соот-

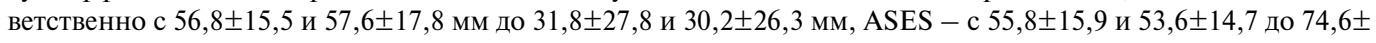

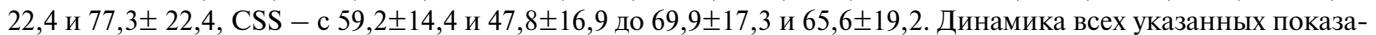
телей по сравнению с исходным уровнем была статистически значимой $(p<0,001)$. Число больных с умеренной/слабой болью (<40 мм визуальной аналоговой шкалы) через 6 мес. после введения обогащенной тромбоцитами плазмы и гиалуроновой кислоты составило 48 и 60\%, нуждающихся в регулярном приеме нестероидных противовоспалительных препаратов - 30 и $28 \%$ соответственно. По всем параметрам различие эффективности обогащенной тромбоцитами плазмы и гиалуроновой кислоты не было статистически значимым $(p>0,05)$. Эффективность обогащенной тромбоцитами плазмы и гиалуроновой кислоты (по динамике боли, ASES и CSS) была существенно выше у лиц моложе 45 лет в сравнении с пациентами более старшего возраста. Переносимость терапии была хорошей - после введения обогащенной тромбоцитами плазмы у 40\% больных отмечалось кратковременное (3-4 дня) усиление боли, которое не требовало применения дополнительных анальгетиков или прерывания лечения. Серьезные неблагоприятные реакции при использовании обогащенной тромбоцитами плазмы и гиалуроновой кислоты не отмечались.

Заключение. Обогащенная тромбоцитами плазма и гиалуроновая кислота эффективны и безопасны при лечении хронической боли в области плеча, связанной с поражением сухожилий мышц вращающей манжеты плеча. Динамика интенсивности боли и функционального статуса после применения этих препаратов не различалась. Лечение обогащенной тромбоцитами плазмой и гиалуроновой кислотой более эффективно у лиц моложе 45 лет.

Ключевые слова: хроническая боль в области плеча, синдром сдавления ротаторов плеча, обогащенная тромбоцитами плазма, гиалуроновая кислота, субакромиальное введение, эффективность, безопасность Для цитирования: Нестеренко В.А., Каратеев А.Е., Макаров М.А., Бялик Е.И., Макаров С.А., Лила А. М. Сравнение эффективности субакромиального введения обогащенной тромбоцитами плазмы и гиалуроновой кислоты при хронической боли в области плеча, вызванной поражением сухожилий мышц вращающей манжеты плеча, по данным 6-месячного открытого клинического исследования. Научнопрактическая ревматология. 2020;58(5):570-576. 


\title{
COMPARISON OF THE EFFECTIVENESS OF SUBACROMIAL ADMINISTRATION OF PLATELET-RICH PLASMA AND HYALURONIC ACID IN CHRONIC SHOULDER PAIN CAUSED BY DAMAGE TO THE TENDONS OF THE ROTATOR CUFF MUSCLES ACCORDING TO A 6-MONTH OPEN CLINICAL STUDY
}

\author{
Vadim A. Nesterenko, Andrey E. Karateev, Maxim A. Makarov, Evgeniy I. Byalik, Sergey A. Makarov, Alexander M. Lila
}

Local injections of platelet-rich plasma (PRP) and hyaluronic acid (HLA) are considered an effective method for treating chronic shoulder pain (CSP) associated with damage to the tendons of the rotator cuff muscles (RCM).

The aim of the study is to compare the effectiveness and safety of local therapy of PRP and HLA in patients with CSP caused by damage to the tendons of the RCM muscles.

Materials and methods. The study included 100 patients ( $54 \%$ women and $46 \%$ men, average age $51.5 \pm 15.1$ years) with CSP (persisting for $\geqslant 3$ months) associated with damage and tendinitis of the supraspinatus, subacute, scapular or small round muscle, confirmed by magnetic resonance imaging or ultrasound (ultrasound). The patients were randomized into two groups of 50 people who were treated with PRP (three injections at 7-day intervals) or HLA (two injections at 7-day intervals). The injections were performed under ultrasound control in the subacromial SAC. The results of the study were evaluated by the dynamics of pain intensity (on a visual analog scale, up to $100 \mathrm{~mm}$ ) and functional disorders (ASES and CSS indices) after 1,3 and 6 months.

Results. Against the background of the use of PRP and HLA, there was a significant improvement in the condition of patients, while both drugs showed approximately the same effectiveness. The severity of VAS pain decreased from $56.8 \pm 15$, respectively, after 6 months.5 and $57.6 \pm 17.8 \mathrm{~mm}$ to $31.8 \pm 27.8$ and $30.2 \pm 26.3 \mathrm{~mm}$, ASES-c $55.8 \pm 15.9$ and $53.6 \pm 14.7$ to $74.6 \pm 22.4$ and $77.3 \pm 22.4$, CSS-c $59.2 \pm 14.4$ and $47.8 \pm 16.9$ to $69.9 \pm 17.3$ and 65.6 \pm 19.2 . the Dynamics of all these indicators in comparison with the baseline level was statistically significant $(p<0.001)$. Number of patients with moderate / mild pain ( $<40 \mathrm{~mm}$ VAS) after 6 months. after the introduction of PRP and HLA was $48 \%$ and $60 \%$, requiring regular NSAID intake $30 \%$ and $28 \%$, respectively. In all parameters, the difference in the effectiveness of PRP and HLC was not statistically significant ( $p>0.05)$. The effectiveness of PRP and HLA (in terms of pain dynamics, ASES, and CSS) was significantly higher in individuals younger than 45 years, compared to older patients. The tolerability of therapy was good - after the introduction of PRP, $40 \%$ of patients had a short-term (3-4 days) increase in pain, which did not require the use of additional analgesics or interruption of treatment. No serious adverse reactions were observed when using PRP and HLA.

Conclusion. OTP and GLA are effective and safe in the treatment of CSP associated with damage to the tendons of the RCM muscles. The dynamics of pain intensity and functional status after the use of these drugs did not differ. Treatment of PRP and HLA is more effective in people younger than 45 years.

Keywords: chronic shoulder pain, shoulder rotator compression syndrome, platelet-rich plasma, hyaluronic acid, subacromial administration, efficacy, safety.

For citation: Nesterenko V.A., Karateev A.E., Makarov M.A., Byalik E.I., Makarov S.A., Lila A.M. Comparison of the effectiveness of subacromial administration of platelet-rich plasma and hyaluronic acid in chronic shoulder pain caused by damage to the tendons of the rotator cuff muscles according to a 6-month open clinical study. Nauchno-Prakticheskaya Revmatologiya=Rheumatology Science and Practice 2020;58(5):570-576 (In Russ.) doi: $10.47360 / 1995-4484-2020-570-576$

Хроническая боль в области плеча (ХБОП) - распространенная патология скелетно-мышечной системы, с которой связаны значительное снижение качества жизни, ограничение профессиональной и повседневной деятельности, а также социальной активности людей преимущественно трудоспособного возраста [1-3]. Согласно результатам анализа 19 исследований, заболеваемость ХБОП колеблется в различных возрастных группах от 0,9 до $2,5 \%$, a ее распространенность варьирует от 4,7 до $46,7 \%$ в течение года и от 6,7 до $66,7 \%$ в течение жизни [4]. В целом боль в плече является одной из ведущих причин обращения к врачу из-за патологии скелетно-мышечной системы, занимая по частоте третье место после боли в спине и остеоартрита (ОА) крупных суставов [5]. Например, по данным голландских исследователей, в течение года частота визитов к врачу в связи с ХБОП составляет от 41,2 до 48,4 на 1000 человеко-лет [6].

В ходе российского исследования ЭНТРОПИЯ было показано, что лица с патологией околосуставных мягких тканей (ПОМТ) составляли $15,8 \%$ от общего потока пациентов на амбулаторном приеме травматологов, занимая по частоте обращений третье место после травм $(37,2 \%)$ и ОА (20,6\%). При этом патология области плеча составила $16,4 \%$ среди всех локализаций ПОМТ [7].

Основной причиной ХБОП является травматическое повреждение сухожилий мышц вращающей манжеты плеча (ВМП), которое наиболее часто возникает в рамках синдрома сдавления ротаторов плеча (ССРП), а также сухожилия длинной головки бицепса, с последующим развитием воспалительных и дегенеративных изменений. При проведении магнитно-резонансной томографии (МРТ) или ультразвукового исследования (УЗИ) признаки тендинита сухожилий мышц ВМП определяются у 70-90\% пациентов с ХБОП [1, 2, 8, 9].

Учитывая распространенность и социальную значимость данной патологии, внедрение в клиническую практику новых и совершенствование уже существующих методов ее лечения относятся к числу важных и актуальных проблем современной медицины.

В последние годы среди методов терапии ХБОП, вызванной повреждением и воспалительно-дегенеративными изменениями связочного аппарата ВМП, важное место заняли локальные инъекции препаратов гиалуроновой кислоты (ГлК) и аутологичной обогащенной тромбоцитами плазмы (ОТП) [1, 2, 10]. Механизм действия этих средств различен, но имеет общее направление - стимуляцию естественных восстановительных процессов в пораженных структурах скелетно-мышечной системы. ГлК улучшает вязко-эластические свойства волокон сухожилия и повышает их устойчивость к механическому стрессу. Кроме этого, ГлК стимулирует синтез эндогенного гиалуроната, восстанавливая межклеточный матрикс перитендиального пространства и способствуя репарации поврежденной ткани [11]. ОТП - богатый источник эндогенных факторов роста, которые содержатся в тромбоцитах и выделяются при их агрегации и разрушении. Хотя механизм действия ОТП изучен недостаточно, считается, что ее эффект может быть связан с ускорением пролиферации и дифференцировки стволовых клеток, что также обеспечивает восстановление поврежденного сухожилия мышц ВМП [12, 13].

Проведена серия рандомизированных контролируемых испытаний (РКИ) и наблюдательных клинических 
исследований, в которых оценивалась эффективность ГлК и ОТП при ХБОП, вызванной ССРП. В целом они демонстрируют значимое (в сравнении с использованием плацебо) уменьшение боли и улучшение функции после курсового применения ГлК и ОТП, особенно при длительном наблюдении ( $\geqslant 6$ мес.) [14, 15]. В то же время имеются лишь единичные работы, в которых сравнивался терапевтический потенциал этих препаратов при данной патологии [16].

Цель исследования: сравнить эффективность и безопасность субакромиального введения ОТП и ГлК при лечении ХБОП, вызванной ССРП.

\section{Материал и методы}

Исследуемую группу составили 100 пациентов (46\% мужчин и $54 \%$ женщин, средний возраст 51,5 $\pm 15,1$ года) с ХБОП. Критериями включения были:

- возраст $\geqslant 18$ лет;

- умеренная или выраженная боль в области плеча ( $\geqslant 40$ мм по 100-мм визуальной аналоговой шкале, ВАШ);

- положительный тест Нира;

- сохранение боли в области плеча $\geqslant 3$ месяцев;

- признаки тендинита и/или дегенеративных изменений сухожилий мышц ВМП (надостной, подостной, подлопаточной и малой круглой), выявленные с помощью УЗИ или МРТ;

- недостаточный эффект проводимой ранее терапии, включая локальные инъекции глюкокортикоидов, прием нестероидных противовоспалительных препаратов (НПВП).

Критериями исключения были наличие системных иммуновоспалительных ревматических заболеваний, при которых отмечается поражение плечевого сустава (ревматоидный артрит, спондилоартриты и др.), наличие противопоказаний для локального введения препарата ГлК и ОТП, наличие серьезных функциональных нарушений или коморбидных заболеваний, препятствующих контрольным визитам.

Характеристика исследуемой группы представлена в таблице 1. Соотношение мужчин и женщин было примерно одинаковым, в основном преобладали лица среднего и пожилого возраста (пациенты младше 45 лет составили около трети всей группы) с преимущественным

Таблица 1. Клиническая характеристика больных $(n=100)$

\begin{tabular}{|c|c|}
\hline Параметры & Значения \\
\hline Пол, женщины/мужчины, \% & $54.0 / 46.0$ \\
\hline Возраст, лет $(M \pm \sigma)$ & $51,5 \pm 15,1$ \\
\hline Число лиц моложе 45 лет, \% & 34,0 \\
\hline Число лиц в возрасте 65 лет и старше, \% & 23,0 \\
\hline 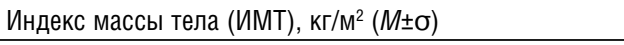 & $26,1 \pm 5,1$ \\
\hline Длительность болезни, мес., Ме [25; 75 перцентиль] & $8[5 ; 24]$ \\
\hline \multicolumn{2}{|l|}{ Патология мышц ВМП (данные УЗИ, МРТ), \%: } \\
\hline Тендинит надостной мышцы & 73,0 \\
\hline Тендинит других мышц ВМП & 27,0 \\
\hline Признаки повреждения сухожилия надостной мышцы & 8,0 \\
\hline Признаки повреждения сухожилий других мышц ВМП & 11,0 \\
\hline Признаки ОА плечевого сустава, \% & 22,0 \\
\hline Признаки ОА акромиально-ключичного сустава, \% & 14,0 \\
\hline Выраженность боли, мм по ВАШ $(M \pm \sigma)$ & $56,8 \pm 16,2$ \\
\hline Индекс ASES $(M \pm \sigma)$ & $54,7 \pm 14,4$ \\
\hline Индекс CSS $(M \pm \sigma)$ & $53,5 \pm 16,7$ \\
\hline
\end{tabular}

поражением надостной мышцы. Около 20\% больных также имели признаки ОА плечевого (гленохумерального) и акромиально-ключичного суставов.

\section{Терапия}

В соответствии с планом исследования 50 больных получали ОТП, 50 - ГлК. Рандомизация достигалась последовательным через одного включением пациентов в исследуемые группы. По основным демографическим и клиническим параметрам группы больных, получавших различные препараты, не различались, за исключением более молодого возраста пациентов и более высокого исходного значения индекса CSS в группе ОTП в сравнении с группой ГлК. Средние значения этих показателей составляли 48,2 $\pm 13,6$ и $54,9 \pm 15,9$ года $(p=0,02)$, $59,2 \pm 14,4$ и 47,8 $\pm 16,9(p=0,004)$ соответственно.

Препарат ОТП изготавливался непосредственно перед введением из аутологичной крови пациента. Процедура получения биологического материала и подготовки препарата была регламентирована компанией-производителем системы для ОТП. Забор крови в количестве 15 мл проводился из вены в специальный двойной шприц-пробирку. Шприц-пробирка помещался в аппарат для центрифугирования, которое проводилось со скоростью 1,5 тыс. оборотов/мин в течение 5 минут. Центрифугирование позволяло разделить цельную кровь на три фракции: нижнюю, состоящую преимущественно из эритроцитов, промежуточную, представленную лейкоцитами, и верхнюю, представляющую собой слой плазмы с содержанием тромбоцитов в диапазоне от 500 до 1700 тыс. в 1 мкл. Вторым шприцем производился забор слоя плазмы с тромбоцитами. Вся процедура осуществлялась в рамках закрытого цикла при строгом соблюдении правил асептики, что исключало контакт с внешней средой и контаминацию ОТП микроорганизмами. Препарат ОТП под УЗИ-контролем вводился в область субакромиальной сумки. Кратность введения ОТП составляла 3 инъекции с интервалом 7 дней. В соответствии с рекомендациями по использованию ОТП на период лечения в течение первого месяца пациентам рекомендовалось воздерживаться от приема НПВП, поскольку действие последних способно снизить влияние факторов роста и замедлить темпы регенерации поврежденной ткани сухожилия.

Препарат ГлК для локального введения представлял собой $2 \%$-ный раствор (2 мл, 40 мг) нативной ГлК, полученной методом бактериальной ферментации (Ост® Тендон). Данный препарат выпускается в виде готового заполненного шприца для инъекций и имеет официальное разрешение для локального введения в область поврежденного сухожилия. В соответствии с инструкцией фирмы-производителя ГлК вводилась под контролем УЗИ в область субакромиальной сумки дважды на курс с интервалом в 1 неделю.

Результат лечения оценивался через 1,3 и 6 месяцев после курса субакромиальных инъекций. Критерием эффективности было уменьшение интенсивности боли (по ВАШ), а также динамика функциональных показателей по опросникам ASES (American Shoulder and Elbow Surgeons Assessment, американская хирургическая система оценки плеча и локтя) и CSS (Constant Shoulder Score, плечевой счет констант).

Для оценки безопасности терапии проводился анализ всех неблагоприятных реакций (НР), которые возникали 
во время проведения терапевтических процедур и в течение последующих 6 мес. наблюдения.

Bce пациенты дали информированное согласие на участие в исследовании. Полученные данные заносились в специальную исследовательскую карту, которая заполнялась по результатам каждого законченного случая с использованием сведений, отмеченных врачом в амбулаторной карте/истории болезни.

Информация из исследовательских карт стала основой для формирования единой компьютерной базы данных и проведения дальнейшего статистического анализа. Для математической обработки данных была использована программа Statistica 12.0. Количественные показатели были представлены в виде $M \pm \sigma$, при отсутствии нормального распределения признака - в виде медианы (Ме), 25-го и 75-го перцентилей, качественные параметры - в виде процентного отношения. При сравнении количественных значений использован критерий Уилкоксона для связанных выборок, критерий Манна - Уитни для независимых выборок, качественных параметров - точный тест Фишера. Различия считались значимыми при $p<0,05$.

\section{Результаты}

Все больные успешно прошли курс инъекционной терапии (как ОТП, так ГлК) и 6-месячный период наблюдения. Случаев прерывания лечения из-за плохой переносимости препаратов, а также выпадения из-под наблюдения отмечено не было.

Уже через 1 месяц после курса инъекций ОТП и ГлК наблюдалось статистически значимое уменьшение боли по ВАШ и улучшение функционального статуса по опросникам ASES и CSS $(p<0,05)$. В дальнейшем достигнутый эффект постепенно нарастал (рис. 1-3). При этом значимых различий по динамике боли и функционального статуса в группах ОТП и ГлК не отмечалось.

Суммарно хороший эффект лечения через 6 мес. наблюдался примерно у половины больных. Так, число пациентов с умеренной/слабой болью (<40 мм по ВАШ) в группах ОТП и ГлК через 1 мес. составило 30 и $40 \%(p=0,147)$, через 3 мес. -48 и $68 \%(p=0,042)$, через 6 мес. -48 и $60 \%$ $(p=0,228)$ соответственно. Число пациентов, у которых на фоне терапии удалось добиться полного или почти полного купирования боли, составило 10 и $4 \%(p=0,239)$, 22 и $16 \%(p=0,101), 28$ и $18 \%$ соответственно $(p=0,234)$. Можно видеть, что через 3 мес. значимо большее число пациентов, получавших ГлК, отметили снижение боли до уровня умеренной или слабой; при этом на всех сроках наблюдения отмечалась тенденция к большей частоте полного или почти полного купирования боли в группе ОТП.

Терапия ОТП и ГлК позволила существенно снизить потребность в регулярном использовании НПВП начиная с первого месяца после курса инъекций (рис. 4). При этом не было отмечено статистически значимого различия в использовании НПВП у больных, получавших ОТП и ГлК.

Учитывая, что исходно между группами больных, получавших ОТП и ГлК, было значимое различие по возрасту, мы провели дополнительную оценку влияния этого фактора на результаты терапии (табл. 2). В целом у пациентов моложе 45 лет результат лечения по всем параметрам был лучше, чем у лиц более старшего возраста. Динамика боли в этих возрастных группах значимо различалась начиная с третьего, изменение индексов ASES и CSS - с первого
Таблица 2. Динамика выраженности боли по ВАШ и функциональных показателей (ASES и CSS) в общей группе больных, получавших ОТП или ГлК, в зависимости от возраста, $M \pm \sigma$

\begin{tabular}{|c|c|c|c|}
\hline \multirow{2}{*}{ Параметры } & & \multicolumn{2}{|l|}{ Возраст } \\
\hline & & $<45$ лет & $\geq 45$ лет \\
\hline \multirow[t]{4}{*}{ Боль, мм по ВАШ } & Исходно & $53,82 \pm 11,81$ & $58,33 \pm 17,93$ \\
\hline & 1 мес. & $36,76 \pm 22,5$ & $43,33 \pm 23,29$ \\
\hline & 3 мес. & $23,82 \pm 23,99^{*}$ & $36,36 \pm 24,65^{*}$ \\
\hline & 6 мес. & $22,35 \pm 26,6^{*}$ & $35,45 \pm 26,20^{*}$ \\
\hline \multirow[t]{4}{*}{ ASES } & Исходно & $59,35 \pm 12,82$ & $52,33 \pm 14,62$ \\
\hline & 1 мес. & $73,02 \pm 18,20^{*}$ & $64,22 \pm 20,20^{*}$ \\
\hline & 3 мес. & $81,91 \pm 18,66^{*}$ & $70,26 \pm 20,88^{*}$ \\
\hline & 6 мес. & $83,26 \pm 20,28 *$ & $72,11 \pm 22,57^{*}$ \\
\hline \multirow[t]{4}{*}{ CSS } & Исходно & $61,86 \pm 14,44^{*}$ & $49,18 \pm 16,16^{*}$ \\
\hline & 1 мес. & $66,94 \pm 15,32^{*}$ & $57,15 \pm 15,68^{*}$ \\
\hline & 3 мес. & $74,07 \pm 16,39^{*}$ & $61,56 \pm 16,68^{*}$ \\
\hline & 6 мес. & $76,32 \pm 16,0^{*}$ & $76,32 \pm 18,08^{*}$ \\
\hline
\end{tabular}

* Значимое различие между группами $(p<0,05)$.

Таблица 3. Динамика выраженности боли (мм по ВАШ) у больных, получавших ОТП и ГлК, в зависимости от возраста [Mе, 25; 75 перцентиль]

\begin{tabular}{lllllll}
\hline & \multicolumn{3}{l}{ Возраст $<$ 45 лет } & \multicolumn{3}{l}{ Возраст $\geq \mathbf{4 5}$ лет } \\
\cline { 2 - 7 } & ОТП & ГлК & $\boldsymbol{p}$ & $\mathbf{0 T \Pi}$ & ГлК & $\boldsymbol{p}$ \\
\hline Исходно & 50 & 50 & 0.619 & 50 & 50 & 0.638 \\
& {$[40 ; 60]$} & {$[42.5 ; 60]$} & & {$[40 ; 70]$} & {$[40 ; 70]$} & \\
\hline 1 мес. & 40 & 35 & 0.377 & 50 & 40 & 0.251 \\
& {$[20 ; 60]$} & {$[12.5 ; 50]$} & & {$[32.5 ; 60]$} & {$[20 ; 50]$} & \\
\hline 3 мес. & 25 & 10 & 0.148 & 50 & 30 & 0.353 \\
& {$[0 ; 50]$} & {$[0 ; 20]$} & & {$[20 ; 50]$} & {$[17.5 ; 42.5]$} & \\
\hline 6 мес. & 10 & 10 & 0.508 & 40 & 30 & 0.592 \\
& {$[0 ; 50]$} & {$[0 ; 42.5]$} & & {$[10 ; 50]$} & {$[10 ; 50]$} & \\
\hline
\end{tabular}

месяца наблюдения. Статистически значимых различий динамики боли, ASES и CSS на фоне лечения ОТП и ГлК у лиц младше 45 лет и пациентов более старшего возраста не выявлено (табл. 3).

За период наблюдения не отмечалось развития серьезных НР, потребовавших отмены терапии или специального лечения. У $40 \%$ пациентов в первые 3-4 дня после инъекций ОТП наблюдалось умеренное усиление боли в области плечевого сустава, не потребовавшее, однако, назначения анальгетиков. В группе больных, получавших ГлК, не было ни одного случая локальных или системных НР.

\section{Обсуждение}

В настоящем исследовании применение ОТП и ГлК позволило добиться существенного улучшения при ХБОП, связанной с ССРП. Оба препарата обеспечивали значимое уменьшение интенсивности боли по ВАШ и функциональных нарушений по опросникам ASES и CSS, причем выраженность терапевтического результата нарастала со временем и была максимальной через 6 мес. после курса лечения. Хороший «ответ» на терапию - уменьшение боли до уровня слабой/умеренной (менее 40 мм по ВАШ) был отмечен примерно у половины больных.

Мы не выявили существенных различий эффективности ОТП и ГлК. В целом результаты применения этих 
препаратов были сопоставимы, за исключением значимо большего числа больных с умеренной/слабой болью на 3-м месяце наблюдения в группе ГлК. При этом на всех сроках наблюдения число пациентов с полным или практически полным купированием боли оказалось несколько выше (не достоверно) в группе ОТП.

Необходимо также отметить существенное снижение потребности в НПВП, которое было достигнуто при использовании как ОТП, так и ГлК, что косвенно подтверждает существенное улучшение состояния большинства пациентов.

Очень важно, что больные хорошо переносили введение ОТП и ГлК и оно не сопровождалось развитием серьезных НР. Кратковременное усиление боли при использовании ОТП является хорошо известным и закономерным явлением, отражающим стимулирующее действие факторов роста. Пациенты были предупреждены об этой НР и перенесли ее совершенно спокойно, тем более что болевые ощущения в этот период носили умеренный характер и быстро прекратились.

Полученные нами данные в целом соответствуют результатам работ зарубежных ученых. Так, M. Lin и соавт. [14] провели метаанализ 5 РКИ $(n=283)$, в которых лечебное действие ОТП сравнивалось с плацебо (локальное введение физиологического раствора (ФР)), отсутствием лечения и физиотерапией. В трех исследованиях анальгетическое действие активной терапии было более выраженным через 12 нед. в сравнении с контролем, однако суммарное отличие было статистически незначимым - стандартизованное различие средних (СРС) 0,25 (95\% доверительный интервал, ДИ $-0,04-0,53, p=0,09)$. Однако через 24 нед. ОТП обеспечивало значимое преимущество: СРС 0,42 (95\% ДИ $0,12-0,72, p=0,006)$. В 4-х исследованиях ОТП также демонстрировала несколько большее улучшение функции через 24 нед. - суммарно СРС $1,2(-0,2-2,6)$, однако эти различия не достигали статистической значимости $p=0,09$.

Успешный опыт применения ОТП при ССРП подтверждает обзор и метаанализ 18 исследований $(n=1116)$, подготовленный X. Chen и соавт. [17]. Полученные данные показали, что применение ОТП может существенно уменьшать боль, улучшать функцию и предупреждать рецидивы заболевания, особенно при длительном сроке наблюдения. В то же время авторы отмечают большую гетерогенность методик терапии ОТП и дизайна исследований, что существенно затрудняет суммарный анализ полученных данных и возможность сформулировать

Рис. 3. Динамика индекса CSS на фроне терапии ОТП (группа 1) и ГлК (группа 2) 
четкие выводы о клинической значимости этого препарата.

В качестве примера можно привести работу D. Rha и соавт. [18], которые сравнили действие ОТП и плацебо (инъекция без введения препарата) у 40 больных ССРП. Через 6 мес. динамика индекса SPDI (Shoulder Pain and Disability Index) в группе ОТП была существенно лучше, чем в контроле - его значение составило в среднем $17,7 \pm 3,7$ и $29,5 \pm 3,8$ соответственно $(p<0,05)$.

В то же время имеются работы, в которых эффективность ОТП при ССРП не была доказана. В качестве примера можно привести РКИ A. Schwitzguebel и соавт. [19], которые сравнили действие ОТП и плацебо (ФР) у 80 больных с подтвержденным при МРТ поражением сухожилия надостной мышцы. Хотя улучшение после введения ОТП было несколько больше, чем в группе плацебо, различие не достигло статистической значимости. Так, динамика боли по ВАШ через 7 мес. составила в среднем $-2,3 \pm 3,0$ и $-2,0 \pm 3,0$ см $(p=0,586)$, через 12 мес. $--3,3 \pm 2,6$ и $-2,3 \pm 3,2$ см $(p=0,087)$ соответственно. Не было и статистически значимых различий динамики функциональных нарушений.

Имеется также доказательная база эффективности ГлК при CCPП. L. Osti и соавт. [15], провели метаанализ 7 РКИ $(n=1102)$. Было показано, что ГлК превосходит по своему действию плацебо и неинъекционные методы лечения, обеспечивая статистически значимое улучшение на длительных сроках наблюдения (6 и 12 мес.).

Y. Huang и соавт. [20] оценили результаты применения ГлК у 18 пациентов с гемиплегией, у которых развилась ХБОП, вызванная поражением сухожилий мышц ротаторов. В контрольную группу вошли 9 больных, получивших инъекции ФР. Через 12 нед. значимое снижение боли наблюдалось у пациентов, получавших ГлК, но не в группе контроля. Медиана боли уменьшилась с 4,0 до $2,5 \mathrm{~cm}(p=0,042)$ и с 4,0 до 3,0 см $(p=0,202)$ соответственно. Близкие данные были получены А. Moghtaderi и соавт. [21], которые провели курс лечения ГлК или ФР 40 больным ССРП. Через 3 нед. у пациентов, получавших активную терапию, интенсивность боли по ВАШ составила в среднем $3,1 \pm 2,4$ см, в группе плацебо $-6,8 \pm 1,9$ см $(p=0,001)$, а индекс CSS через 12 нед. $70,4 \pm 16,9$ и 50,7 $\pm 13,2$ соответственно $(p<0,001)$.

Нам удалось найти лишь одно исследование, в котором сравнивалась эффективность ОТП и ГлК при ХБОП, связанной с ССРП. Это РКИ, выполненное Ү. Саі и соавт. [16], в ходе которого оценивалось лечебное действие ОТП, ГлК, комбинации ОТП и ГлК и плацебо (ФР) у 184 больных ССРП. Активная терапия была достоверно более эффективна, чем плацебо,- интенсивность боли составила через 3 мес. 4,62, 4,02, 3,69 и 5,3 см; через 6 мес. $-2,82,3,45,2,35,5,85$ см; через 12 мес. $-1,98$, $2,89,1,25,6,87$ см соответственно $(p<0,05)$. Аналогичный результат был отмечен при оценке ASES и CSS. ОTП и комбинация ГлК и ОТП были несколько эффективнее, чем монотерапия ГлК, однако эти различия не достигали статистической значимости.

Следует отметить, что все исследователи отмечают хорошую переносимость ОТП и ГлК у пациентов с ХБОП и низкую частоту НР при использовании этих препаратов, сопоставимую с соответствующим показателем для плацебо $[14,15]$.

Мы наблюдали зависимость эффекта ОТП и ГлК от возраста пациентов. По динамике интенсивности боли, индексов ASES и CSS результаты были значимо лучше у лиц моложе 45 лет. Эта закономерность отмечалась при использовании как ОТП, так и ГлК. Можно предположить, что относительно молодые пациенты имеют более высокий регенеративный потенциал, чем люди старшего возраста $[22,23]$. Поэтому применение ОТП и ГлК, стимулирующих восстановительные процессы в поврежденных сухожилиях мышц, обеспечивает более быстрое и значимое улучшение состояния при ССРП у молодых пациентов.

Таким образом, субакромиальное введение препаратов ОТП и ГлК может считаться эффективным и безопасным методом лечения ХБОП, связанной с ССРП. Оба этих средства оказывают сопоставимое терапевтическое действие, снижая интенсивность боли и улучшая функцию плечевого сустава. Эффективность ОТП и ГлК существенно выше у лиц моложе 45 лет, поэтому использование данных препаратов более перспективно при относительно небольшой давности заболевания у молодых пациентов.

\section{Прозрачность исследования}

Исследование не имело спонсорской поддержки. Авторы несут полную ответственность за предоставление окончательной версии рукописи в печать.

Декларация о финансовых и других взаимоотношениях

Все авторы принимали участие в разработке концепции статьи и в написании рукописи. Окончательная версия рукописи была одобрена всеми авторами. Авторы не получали гонорар за статью. 


\section{СПИСОК ЛИТЕРАТУР Ы / REFERENCES}

1. Micallef J., Pandya J., Low A.K. Management of rotator cuff tears in the elderly population. Maturitas. 2019;123:9-14. DOI: 10.1016/j.maturitas.2019.01.0

2. Ramme A.J., Robbins C.B., Patel K.A., Carpenter J.E., Bedi A., Gagnier J.J., Miller B.S. Surgical Versus Nonsurgical Management of Rotator Cuff Tears: A Matched-Pair Analysis. J Bone Joint Surg Am. 2019;101(19): 1775-1782. DOI: $10.2106 / J B J S .18 .01473$

3. Page M.J., O'Connor D.A., Malek M., Haas R., Beaton D., Huang H., et al. Patients' experience of shoulder disorders: a systematic review of qualitative studies for the OMERACT Shoulder Core Domain Set. Rheumatology (Oxford). 2019. PII: kez046. DOI: 10.1093/rheumatology/kez046

4. Luime J.J., Koes B.W., Hendriksen I.J., Burdorf A., Verhagen A.P., Miedema H.S., Verhaar J.A. Prevalence and incidence of shoulder pain in the general population; a systematic review. Scand J Rheumatol. 2004;33(2):73-81. DOI: $10.1080 / 03009740310004667$

5. Dougados M., Le Henanff A., Logeart I., Ravaud P. Short-term efficacy of rofecoxib and diclofenac in acute shoulder pain: a placebo-controlled randomized trial. PLoS Clin Trials. 2007;2(3):e9. DOI: $10.1371 /$ journal.pctr.0020009

6. Greving K., Dorrestijn O., Winters J.C., Groenhof F., van der Meer K., Stevens M., Diercks R.L. Incidence, prevalence, and consultation rates of shoulder complaints in general practice. Scand J Rheumatol. 2012;41(2):150-155.

DOI: 10.3109/03009742.2011.605390

7. Каратеев А.Е., Лила А.М., Загородний Н.В., Погожева Е.Ю. Поражение околосуставных мягких тканей в реальной клинической практике: частота, характер, эффективность нестероидных противовоспалительных препаратов. Терапевтический архив. 2019;91(12):21-28. [Karateev A.Е., Lila A.M., Zagorodny N.V., Pogozheva E. Yu. Lesion of periarticular soft tissues in real clinical practice: frequency, nature, effectiveness of non-steroidal anti-inflammatory drugs. Terapevticheskiy arkhiv $=$ Therapeutic archive. 2019;91(12):21-28. (In Russ.)] DOI: 10.26442/00403660.2019.12.000377

8. Chang R.F., Lee C.C., Lo C.M. Quantitative diagnosis of rotator cuff tears based on sonographic pattern recognition. PLoS One. 2019;14(2):e0212741. DOI: 10.1371/journal.pone.0212741

9. Lewis J. Rotator cuff related shoulder pain: Assessment, management and uncertainties. Man Ther. 2016;23:57-68. DOI: 10.1016/j.math.2016.03.009

10. Lin K.M., Wang D., Dines J.S. Injection Therapies for Rotator Cuff Disease. Orthop Clin North Am. 2018;49(2):231-239. DOI: 10.1016/j.ocl.2017.11.010

11. Moraes V.Y., Lenza M., Tamaoki M.J., Faloppa F., Belloti J.C. Platelet-rich therapies for musculoskeletal soft tissue injuries. Cochrane Database Syst Rev. 2014;(4):CD010071. DOI: 10.1002/14651858.CD010071.pub3

12. Gallorini M., Berardi A.C., Berardocco M., Gissi C., Maffulli N., Cataldi A., Oliva F. Hyaluronic acid increases tendon derived cell viability and proliferation in vitro: comparative study of two different hyaluronic acid preparations by molecular weight. Muscles
Ligaments Tendons J. 2017;7(2):208-214.

DOI: $10.11138 / \mathrm{mltj} / 2017.7 .2 .208$

13. Osti L., Berardocco M., di Giacomo V., Di Bernardo G., Oliva F., Berardi A.C. Hyaluronic acid increases tendon derived cell viability and collagen type I expression in vitro: Comparative study of four different Hyaluronic acid preparations by molecular weight. BMC Musculoskelet Disord. 2015;16:284.

DOI: 10.1186/s12891-015-0735-7

14. Lin M.T., Wei K.C., Wu C.H. Effectiveness of Platelet-Rich Plasma Injection in Rotator Cuff Tendinopathy: A Systematic Review and Meta-Analysis of Randomized Controlled Trials. Diagnostics (Basel). 2020;10(4). PII: E189. DOI: $10.3390 /$ diagnostics 10040189

15. Osti L., Buda M., Buono A.D., Osti R., Massari L. Clinical evidence in the treatment of rotator cuff tears with hyaluronic acid. Muscles Ligaments Tendons J. 2016;5(4):270-275. DOI: $10.11138 / \mathrm{mltj} / 2015.5 .4 .270$

16. Cai Y.U., Sun Z., Liao B., Song Z., Xiao T., Zhu P. Sodium Hyaluronate and Platelet-Rich Plasma for Partial-Thickness Rotator Cuff Tears. Med Sci Sports Exerc. 2019;51(2):227-233. DOI: 10.1249/MSS.0000000000001781

17. Chen X., Jones I.A., Togashi R., Park C., Vangsness C.T. Jr. Use of Platelet-Rich Plasma for the Improvement of Pain and Function in Rotator Cuff Tears: A Systematic Review and Metaanalysis With Bias Assessment. Am J Sports Med. 2019:363546519881423. DOI: 10.1177/0363546519881423

18. Rha D.W., Park G.Y., Kim Y.K., Kim M.T., Lee S.C. Comparison of the therapeutic effects of ultrasound-guided platelet-rich plasma injection and dry needling in rotator cuff disease: a randomized controlled trial. Clin Rehabil. 2013;27(2):113-122. DOI: $10.1177 / 0269215512448388$

19. Schwitzguebel A.J., Kolo F.C., Tirefort J., Kourhani A., Nowak A., Gremeaux V., et al. Efficacy of Platelet-Rich Plasma for the Treatment of Interstitial Supraspinatus Tears: A Double-Blinded, Randomized Controlled Trial. Am J Sports Med. 2019;47(8):1885-1892. DOI: 10.1177/0363546519851097

20. Huang Y.C., Leong C.P., Tso H.H., Chen M.J., Liaw M.Y., Hsieh H.C., et al. The long-term effects of hyaluronic acid on hemiplegic shoulder pain and injury in stroke patients: A randomized controlled study. Medicine (Baltimore). 2018;97(35):e12078. DOI: 10.1097/MD.0000000000012078

21. Moghtaderi A., Sajadiyeh S., Khosrawi S., Dehghan F., Bateni V. Effect of subacromial sodium hyaluronate injection on rotator cuff disease: A double-blind placebo-controlled clinical trial. Adv Biomed Res. 2013;2:89. DOI: 10.4103/2277-9175.122517

22. Cheng M., Johnson V.M., Murray M.M. Effects of age and platelet-rich plasma on ACL cell viability and collagen gene expression. J Orthop Res. 2012;30(1):79-85. DOI: $10.1002 /$ jor.21496

23. Gabusi E., Paolella F., Manferdini C., Gambari L., Schiavinato A., Lisignoli G. Age-independent effects of hyaluronan amide derivative and growth hormone on human osteoarthritic chondrocytes. Connect Tissue Res. 2015;56(6):440-451. DOI: $10.3109 / 03008207.2015 .1047928$
Нестеренко B.A. ORCID: $h$ ttps://orcid.org/0000-0002-7179-817
Каратеев A.E. ORCID: $h$ ttps://orcid.org/0000-0002-1391-0711
Макаров M.A. ORCID: https://orcid.org/0000-0002-5626740
Бялик E.И. ORCID: https://orcid.org/0000-0001-7938-153
Макаров C.A. ORCID: https:///orcid.org/0000-0001-8563-063
Лила A.M. ORCID: https://orcid.org/0000-0002-6068-3080 